\title{
A relação de um estudante surdo de uma escola pública com o saber
}

\section{The relationship of a deaf student from a public school to knowledg}

https://doi.org/10.34112/2317-0972a2021V39n82pg1-107

Willdson Robson Silva do Nascimento ${ }^{1}$

Eder Pires de Camargo ${ }^{2}$

Eanes dos Santos Correia ${ }^{3}$

ResumO: A pesquisa tem como objetivo analisar alguns resultados da presença do intérprete de Língua Brasileira de Sinais (Libras) em sala de aula a partir das experiências explicitadas por um estudante surdo recém-concluinte do ensino médio em uma instituição de ensino público do estado de Sergipe. Trata-se de uma pesquisa qualitativa do tipo exploratório-descritiva, tendo como instrumento de constituição de dados a entrevista semiestruturada e a organização de dados, baseada em alguns elementos da Análise de Discurso. E como suporte teórico utilizaram-se a Relação com o Saber, de Bernard Charlot, e a noção do Duplo Triângulo Pedagógico, de Correia, Silva, Nascimento e Charlot. Os resultados demonstram alguns efeitos da presença do intérprete de Libras para o estudante surdo, que se materializam através do "aprender", "mais vontade de estudar" e "Eles fazem a mediação da aula".

PALAVRAS-CHAVE: Estudante surdo; escola pública; relação com o saber; intérprete.

ABSTRACT: The research aims to analyze some results of the presence of the Brazilian Sign Language (Libras) interpreter in the classroom from the experiences reported by a deaf student who has just finished high school at a public education institution in the state of Sergipe. This is an exploratory-descriptive qualitative research, using semi-structured

1. Universidade Estadual Paulista "Júlio de Mesquita Filho", Bauru, SP, Brasil.

2. Universidade Estadual Paulista "Júlio de Mesquita Filho", Ilha Solteira, SP, Brasil.

3. Universidade Federal de Sergipe, São Cristóvão, SE, Brasil. 
interviews and data organization as a data constitution instrument, based on some elements of Discourse Analysis. As a theoretical support it was used the Relation with Knowledge, by Bernard Charlot, and the notion of the Pedagogical Double Triangle, by Correia, Silva, Nascimento and Charlot. The results demonstrate some effects of the presence of the called Libras interpreter for the deaf student, which materialize through "learning", "more willingness to study" as well as mediate the class"

KEYwORDS: Deaf student; public school; relationship with knowledge; interpreter.

\section{INTRODUÇÃo}

A Lei 10.436, de 24 de abril de 2002, foi sancionada há exatamente 19 anos, e por meio dela a Língua Brasileira de Sinais (Libras) foi reconhecida como meio legal de comunicação e expressão da comunidade surda. Utiliza-se esse fato como mais um catalizador para se construir um diálogo sobre o papel do intérprete de Libras na formação de vários estudantes surdos e surdas, matriculados na escola pública regular no Brasil, conforme a Lei n. ${ }^{\circ}$ 12.796, de 4 de abril de 2013 , que determina em seu Art. 4, inciso III: "Atendimento educacional especializado gratuito aos educandos com deficiência, transtornos globais do desenvolvimento e altas habilidades ou superdotação, transversal a todos os níveis, etapas e modalidades, preferencialmente na rede regular de ensino" (BRASIL, 2013).

$\mathrm{O}$ direito adquirido precisa se alinhar e respeitar o processo de aprendizagem desses estudantes, que demanda uma educação bilíngue desde a educação infantil, pois é por meio dela que os estudantes surdos irão construir a dimensão da sua identidade cultural e compor um canal de comunicação com o mundo.

Explica-se que a grande maioria das crianças surdas nasce em lares ouvintes (REILY, 2006) e, por essa razão, precisam da língua de sinais, na escola de educação infantil - sua trajetória educacional inicial -, para se apropriarem do mundo e reconhecerem a Libras como língua primeira, a língua que lhes possibilitará construir relações. E, a partir desse primeiro passo, poderão compreender a mediação do intérprete dentro da sala de aula, para se apropriarem dos conhecimentos do mundo. Assim, estarão construídas as possibilidades para que o estudante surdo aprenda o português e a Libras, para que ele ou ela possa compreender melhor a leitura e a escrita compartilhada entre as comunidades surda e ouvinte. 
Bem evidente é o ordenamento jurídico respaldado na Lei ${ }^{\circ}$ 13.146, de 6 de julho de 2015 (Estatuto da Pessoa com Deficiência), no seu Capítulo IV, Do Direito à Educação, Art. 27 e Art. 28, ao afirmar:

Art. 27. A educação constitui direito da pessoa com deficiência, assegurados sistema educacional inclusivo em todos os níveis e aprendizado ao longo de toda a vida, de forma a alcançar o máximo desenvolvimento possível de seus talentos e habilidades físicas, sensoriais, intelectuais e sociais, segundo suas características, interesses e necessidades de aprendizagem.

Art. 28. Incumbe ao poder público assegurar, criar, desenvolver, implementar, incentivar, acompanhar e avaliar.

Segundo esse documento - o Estatuto da Pessoa com Deficiência (BRASIL, 2015) -, o processo de inclusão dos estudantes surdos nas escolas reivindica espaços mais humanitários e práticas pedagógicas que busquem a valorização da socialização, bem como o uso da Libras como uma língua viva, em movimento e construção naquele espaço. É indispensável que professores e professoras, pais e familiares compreendam a responsabilidade social e legal da língua de sinais para o processo de humanização do sujeito surdo. É através dessa língua que o surdo poderá exercer seus direitos, bem como exigi-los.

Nesta senda, Charlot (2005) destaca que é pela educação que o ser humano é construído e que essa educação é o resultado de um triplo processo: de humanização, construir-se humano; de socialização, adentrar um grupo social e cultural e de singularização e subjetivação e dele participar, ter uma história de vida. Assim, é possível compreender que não se pode isolar a questão social da questão da identidade do sujeito, ou seja, "aprender faz sentido por referência a história do sujeito, às suas expectativas, às suas referências, à sua concepção de vida, às suas relações com os outros, à imagem que tem de si e à que quer dar de si aos outros" (CHARLOT, 2000, p. 72).

Diante desse contexto é que esta pesquisa ganha relevância e robustez, ao trazer discussões que possam fortalecer o ensino inclusivo, baseadas nas experiências dos autores nos campos acadêmico, profissional e pessoal com a temática da inclusão.

No tocante ao tema proposto, este trabalho se caracteriza como uma pesquisa qualitativa. Tem como questão central: "Qual o papel do intérprete de Libras 
em sala de aula regular, na escola pública, para o processo de aprendizagem do estudante surdo?" e seu objetivo é analisar alguns resultados da presença do intérprete de Libras em sala de aula, a partir das experiências explicitadas por um estudante surdo recém-concluinte do ensino médio em uma instituição de ensino público do estado de Sergipe.

A seguir, apresentaremos o aprofundamento teórico sobre o processo de ensino e aprendizagem do estudante surdo a partir da perspectiva da Relação com o Saber e o percurso metodológico que sustenta a pesquisa.

\section{Metodologia}

Esta investigação, como já apontamos, caracteriza-se como qualitativa. Segundo Chizzotti (2006), a pesquisa qualitativa se fundamenta na relação dinâmica entre o sujeito e o mundo e na correlação entre o sujeito e o objeto. Assim, para compor a busca por respostas, utilizamos como instrumento de constituição de dados a entrevista semiestruturada, apoiada na concepção de Flick (2009). Esta escolha permite a análise do discurso do entrevistado, além de proporcionar dados comparáveis entre os sujeitos participantes da pesquisa.

Nessa perspectiva, a constituição do corpus de análise tem como sujeito um estudante surdo recém-concluinte do ensino médio de uma escola pública do estado de Sergipe. A entrevista procurou abranger três eixos de questionamentos: a relação do intérprete com o professor da sala de aula; a importância do intérprete para a formação do estudante surdo; e as metodologias de ensino utilizadas pelos professores em suas aulas.

Nesse contexto, para a preservação ética dos envolvidos, eles serão aqui nomeados de: E - Entrevistador; E1 - Estudante surdo recém-concluinte do $3 .^{\circ}$ ano do ensino médio. Para obtermos as informações do estudante surdo, utilizamos o auxílio de um intérprete de Libras nos seguintes casos: interpretação de Libras/Português e Português/Libras. Além disso, nos casos em que utilizamos um aplicativo de mensagem instantânea para tirar dúvidas a posteriori com o estudante surdo, o intérprete nos auxiliou na tradução, para o português formal, das mensagens em português escritas pelo estudante, que tem o português como sua segunda língua (L2). 
O PROCESSO DE ENSINO E APRENDIZAGEM DO ESTUDANTE SURDO E A RELAÇÃO COM O SABER

Na busca pela compreensão do relacionamento ternário que ocorre na didática das matemáticas, Chevallard (2005) introduz o sistema didático (Figura o1) como uma possibilidade teórica para seus princípios. Um relacionamento didático marcado por três posicionamentos, $\mathrm{P}$ (professor), $\mathrm{S}$ (Saber) e Estudante (E), atrelados às suas inter-relações.

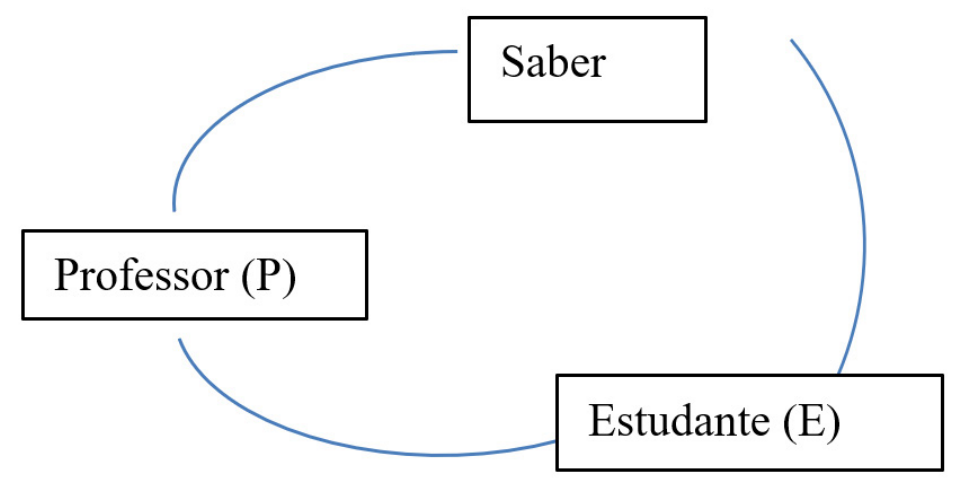

Figura 1: Sistema didático na concepção de Chevallard - Fonte: Estudos realizados por Chevallard (2005)

É importante destacar que o formato triangular, base que sustenta a afinidade entre professor, estudante e saber no sistema didático de Chevallard (2005), também já foi utilizado para fundamentar a relação educativa por outros autores, como Arruda e Passos (2015) e outros pesquisadores, a exemplo de Correia, Silva, Nascimento e Charlot (2020).

Nessa perspectiva é que vamos considerar o trabalho já realizado por Correia, Silva, Nascimento e Charlot (2020) sobre o Duplo Triângulo Pedagógico (Figura 02), para sustentar a nossa interpretação. O Duplo Triangulo Pedagógico tem base fundamental na Relação com o Saber, trazendo a problemática da relação entre ensino e aprendizagem por meio da dimensão epistêmica, social e identitária, associada ao Triângulo Pedagógico Professor, Estudante e Saber. Para os autores, 
essas dimensões se estabelecem de forma associativa, uma vez que não são consideradas aditivas e nem podem ser, pois o ensinar e aprender não podem ser compreendidos como uma soma das dimensões, mas são indissociáveis quando se trata do processo de ensino e aprendizagem em quaisquer instâncias da seara didático-pedagógica da educação. (CORREIA; SILVA; NASCIMENTO; CHARLOT, 2020, p. 8).

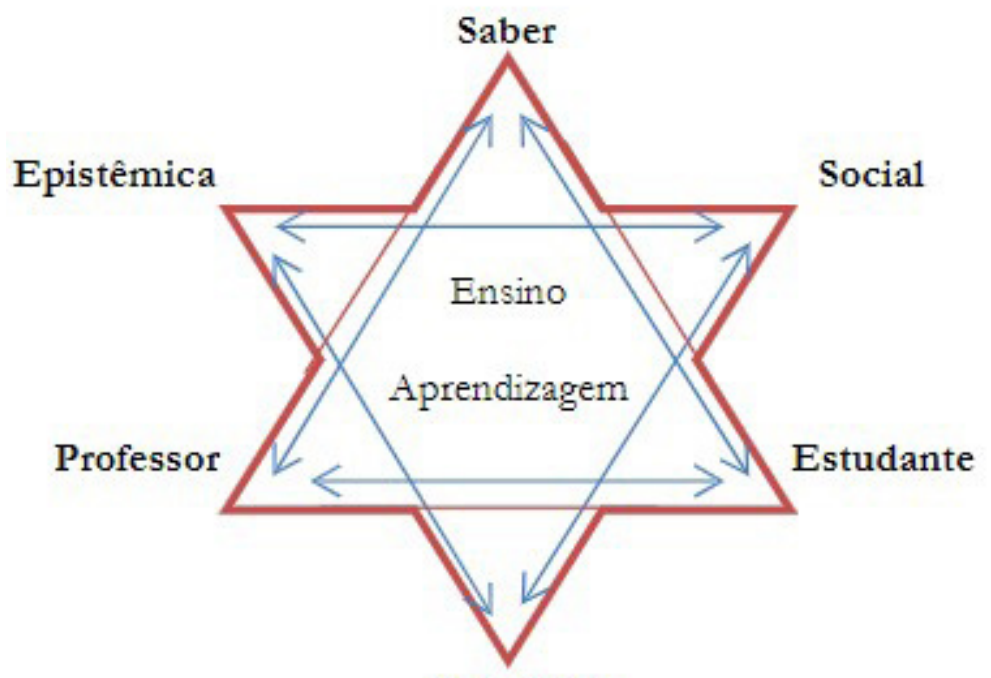

Identitária

Figura 2: Duplo Triângulo Pedagógico - Fonte: Correia, Nascimento, Silva e Charlot (2020, p. 7)

É dentro dessa perspectiva que desenvolveremos uma relação entre o Intérprete (I), o Professor (P) e o Estudante (E). Conferindo que os interesses de Correia, Silva, Nascimento e Charlot (2020) também estavam voltados para o processo de ensino e aprendizagem na perspectiva da Relação com o Saber é que trouxemos suas contribuições para esta pesquisa.

A Relação com o Saber é uma interpretação dinâmica das relações que o ser humano estabelece ao longo da sua historicidade - consigo mesmo, com o outro e com o mundo (CHARLOT, 200o). O ser humano, na perspectiva da Relação com o Saber, é reconhecido a partir de suas histórias, crenças, de seus valores, cultura, posição social, etc.; e, portanto, é acolhido como um sujeito. 
É importante destacar, em conformidade com Charlot (2000, p. 79), que um pesquisador que estuda a Relação com o Saber "estuda relações com lugares, pessoas, objetos, conteúdos de pensamento, situações, etc.", ou seja, interessa-se pela relação do sujeito com seu exterior, buscando analisar essa relação simbólica, ativa e temporal na qual o sujeito se encontra imerso. Imerso no mundo da linguagem, de significados e de atividade.

Diante dessa intencionalidade é que esta pesquisa se constrói, na tentativa de analisar o produto de relações epistemológicas entre o intérprete de Libras, o estudante e o professor, uma vez que essas relações são necessárias tanto para construir o saber quanto para sustentá-lo após sua construção.

Segundo as ideias de Charlot (200o), o sujeito traz consigo marcas do ser social e singular que o constitui, ou seja, ao longo da sua vida, ele vem ocupando uma posição social e construindo uma subjetividade orientada por um psiquismo específico, além de produzir sentidos e significados com o mundo a partir de um envolvimento íntimo e organizado, inscrito em certo tempo e espaço de atividade (CHARLOT, 2000).

Nesse contexto é que Charlot (2000) propõe reflexões, estudos e investigações sobre uma sociologia do sujeito, ou seja, uma sociologia que parte do pressuposto de que o sujeito é um conjunto de relações e processos. Assim, "o sujeito é relação com o saber" (CHARLOT, 2000, p. 82).

A esse respeito, Charlot (2000, p. 46) nos lembra de que "toda relação consigo é também relação com o outro, e toda a relação com o outro é também relação consigo próprio". Em outras palavras, uma sociologia do sujeito se fundamenta na necessidade que temos do outro no nosso processo de humanização, socialização e educação.

A educação é uma construção individual e intencional de nós mesmos, porém essa autoalimentação do conhecimento só é possível pela mediação do outro e com a ajuda dele (CHARLOT, 2000). É através da educação que uma criança, que nasce inacabada antropologicamente, se desenvolve e se constrói enquanto um sujeito social, singular e exposto a recursos que ofereçam sentido, desejo e prazer e promovam a entrada numa atividade intelectual de aprendizagem, de modo que a criança vá encontrando a sua "boa razão" (NASCIMENTO, 2018, p. 133) para se mobilizar.

A mobilização implica na utilização de si mesmo como recurso para aprender, é "engajar-se em uma atividade" (CHARLOT, 2000, p. 55) que faça sentido para o estudante, de forma que ele encontre um motivo e uma meta para "pôr-se em movimento" (CHARLOT, 2000, p. 54) na direção do seu processo de aprendizagem. 
É nesse âmbito que esse estudante é compreendido nas suas dimensões social, epistêmica e identitária da Relação com o Saber, uma vez que o processo educacional só é possível se a criança, pela mediação do professor, encontrar no mundo os recursos necessários que vão lhe permitir construir-se (CHARLOT, 2000).

A dimensão epistêmica aborda o modo como o estudante aprende, de que forma ele se expõe e se dispõe para entrar em uma atividade para aprender. A dimensão social expressa as condições sociais desse estudante e suas relações na sociedade. Já a dimensão identitária caracteriza o encontro do estudante consigo mesmo, traz à tona a idiossincrasia de cada sujeito, compreendendo a formação da sua identidade a partir de sua história (NASCIMENTO; CAMARGO; CORREIA; SILVA, 2019).

Outro aspecto na compreensão das três dimensões supracitadas é que elas são indissociáveis, ocorrem simultaneamente, bem como não se fragmentam da correspondência entre ensino e a aprendizagem. Por conseguinte, estudar a relação de um estudante com o saber é perceber as relações epistêmicas, sociais e identitárias desse sujeito dentro da seara educacional (NASCIMENTO, 2018).

Nessa perspectiva, com base na Relação com o Saber e a partir da interpretação de Correia, Silva, Nascimento e Charlot (2020) é que vamos refletir sobre a relação entre o Intérprete de Libras (I), o Professor (P) e o Estudante (E) na estrutura do duplo triângulo pedagógico reinterpretado (Figura 03).

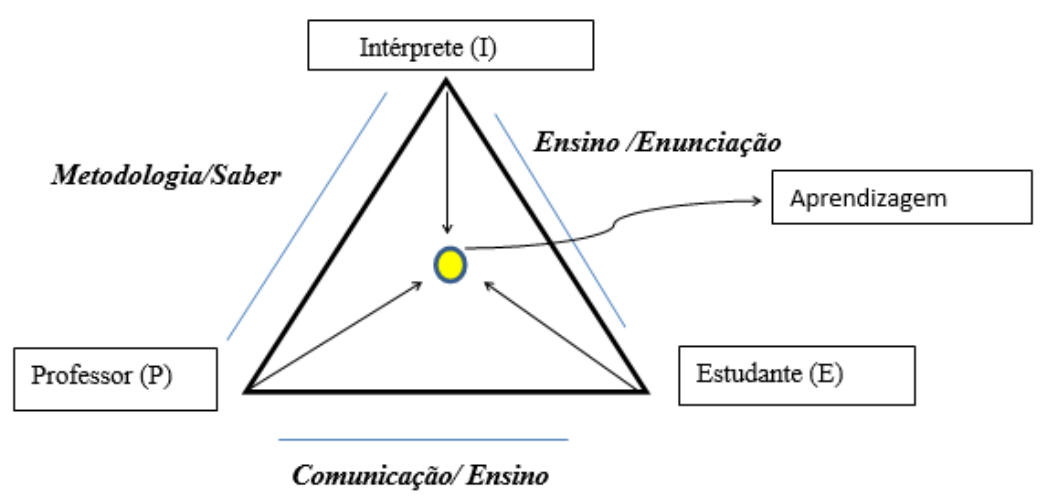

Figura 3: Duplo Triangulo Pedagógico Reinterpretado - Fonte: Elaborado pelos autores (2020)

Dessa forma, entendemos a Figura 03 como uma estrutura formada pelos vértices: Intérprete (I), Professor (P) e Estudante (E), em que os lados ou arestas são interpretados como: 
$\mathrm{I}$ - $\mathrm{P}=$ indica a relação entre o Intérprete (I) e o Professor $(\mathrm{P})$, em que I pode ser compreendido como um auxiliador do saber, uma vez que o professor (P) é o responsável por essa mediação. Em outras palavras, I é auxiliador e divulgador das competências e habilidades construídas ao longo da formação profissional de $\mathrm{P}$, bem como de suas próprias experiências em sala de aula. Essa relação entre I e P representa a Metodologia e o Saber desses dois profissionais em sala de aula, para mediatizar para o estudante surdo o processo de apropriação do saber, mediante a comunicação; I - E= indica a relação entre o Intérprete (I) e o Estudante (E) surdo, assim como representa o Ensino e a Comunicação estabelecida entre esses dois sujeitos do processo; $\mathrm{P}-\mathrm{E}=$ indica a relação entre o Professor (P) e o Estudante (E) surdo, do mesmo modo que representa a Comunicação e o Ensino mediados pelo Intérprete (I).

Portanto, entendemos as relações construídas entre esses sujeitos como uma possibilidade para percorrermos o caminho até a aprendizagem - o baricentro do triângulo - de um estudante surdo, a partir do seguinte percurso: primeiro, $o$ Professor (P), de posse de metodologias diversas, que explorem a percepção, a forma de estabelecer relações e a comunicação com o Estudante (E) surdo, desenvolve um ambiente de mediação, colaboração, compartilhamento e de empatia. Para mais, o Professor $(\mathrm{P})$, expondo uma didática flexível e reorganizada para a mediação do seu saber, de forma a evitar apenas o diálogo oral e atividades escritas em uma sala com a presença de um estudante surdo, uma vez que a língua do surdo é visual-espacial e pode construir uma parceria inclusiva com o intérprete, planejando suas ações, de forma aberta a possibilidades metodológicas.

O Intérprete (I), por sua vez, diante dessa metodologia e didática apresentadas pelo Professor $(\mathrm{P})$, está apto a mediar o ensino e enunciar com o estudante surdo. A enunciação, segundo Fiorin (2020), é o ato de produzir enunciados, ou seja, é o ato de dizer. E para dizer algo - neste caso, sinalizar algo - é preciso ter o conhecimento internalizado de determinada língua. Nesse caso, o Intérprete tem o conhecimento internalizado da Libras e, portanto, consegue enunciar para o estudante surdo.

Essa enunciação apresenta algumas características próprias - por exemplo, um conteúdo específico (Matemática, Física, Química, Português, etc.), a pessoa do discurso (quem sinaliza), a pessoa apta a receber o discurso sinalizado (o estudante), o espaço em que acontece (sala de aula) e o tempo (momento da aula). Desse modo, um canal comunicativo é construído com o estudante surdo, com base nessas características, possibilitando que o ensino chegue até ele. 
O Estudante (E) surdo, um sujeito histórico, social e cultural, tendo a cultura surda internalizada, para permitir que o ensino chegue até ele pela mediação do Intérprete, será capaz de enunciar diretamente ao seu Professor $(\mathrm{P})$ suas dúvidas e questionamentos a respeito da aula ministrada.

Vale destacar que, nesse triângulo, o Professor (P) é o responsável pelo ensino do estudante surdo e que essa responsabilidade não pode ser atribuída ao Intérprete (I). Esse profissional precisa manter um posicionamento ético neutro, sendo fiel à tradução metodológica do professor.

A aprendizagem, por outro lado, vai depender do estudante surdo. É um ato individual, intencional e íntimo do estudante com o saber que está sendo exposto para ele. Não se aprende sem esforço (NASCIMENTO, 2018). Portanto, só aprende quem encontra sentido, desejo, prazer, e entra em uma atividade intelectual - variáveis que são molas propulsoras da mobilização. E essas variáveis são induzidas pelas relações construídas consigo mesmo (dimensão identitária), com o outro (dimensão epistêmica) e com o mundo (dimensão social).

\section{Resultados E Discussões}

Para compreender o universo dos discursos envolvidos neste trabalho, utilizaremos alguns elementos da análise de discurso para perceber a construção do sentido do sujeito entrevistado quando se dirige a outro sujeito - neste caso, o entrevistador. A seguir, o discurso do estudante.

\section{ENTREVISTA COM E1}

Para realizarmos essa entrevista, contamos com o apoio de um intérprete de Libras com encontro presencial, além de termos criado um contato direto com o estudante por meio de um aplicativo de mensagens instantâneas para dúvidas posteriores. Nesse último caso, para as mensagens que foram enviadas pelo aplicativo e respondidas pelo estudante, tivemos a ajuda do profissional intérprete, presente na pesquisa na modalidade escrita da tradução do português como L2 para o português formal.

O estudante surdo participante acaba de concluir o seu ensino médio, pertence a uma família de classe popular, e seus familiares não sabem a Libras. Ele nos relata que não quer trabalhar após terminar os estudos, e, sim, fazer uma faculdade e está procurando um curso. Quando questionado sobre qual seria esse curso, nos 
diz que seria tecnologia ou robótica, por gostar muito de mexer no computador e consertar objetos eletrônicos. Após os primeiros questionamentos, na tentativa de deixá-lo à vontade, perguntamos:

E: Pode contar como tem sido a escola para ti desde que começaste a frequentá-la?

E1: Um pouco difícil pelo fato de não entender muito os professores, mas com a ajuda das intérpretes consegui aprender sem muitas dificuldades.

E: Você começou a frequentar a escola com quantos anos?

E1: 3 anos.

E: Sempre teve intérprete?

E1: Não, teve anos que eu ficava sem.

E: E como fazia quando não tinha o intérprete?

E1: Era muito difícil, muito difícil, eu não aprendia nada.

E: O que te faz ir à escola todos os dias?

E1: Mais para me divertir, distrair a mente e aprender com os professores e todos.

O discurso do estudante revela que a dificuldade no canal de comunicação dele com o professor e, por consequência, com o saber, o levaram a momentos difíceis durante seu processo de escolarização, o que é reforçado quando ele afirma que nem sempre teve intérprete em sala de aula. Ao buscar na sua memória esses fatos, o sujeito expõe a produção do seu discurso, ou seja, revisita uma rede de memórias (mítica, social e da memória construída pelo sujeito) (PÊCHEUX, 2010). Para Orlandi (2009, p. 30), "a maneira como a memória 'aciona', faz valer, as condições de produção”. Ainda para a autora, as condições de produção em um sentido mais estrito, partindo das circunstâncias da enunciação, residem no contexto imediato. E em sentido mais amplo, podemos incluir o contexto sócio-histórico e ideológico.

É importante destacar que o sentido atribuído ao estudante para ir à escola está relacionado com o fato de se divertir, distrair a mente e aprender, ou seja, ele gosta da escola, o que também foi percebido por Charlot (2012) em estudo na França com estudantes ouvintes: quando um estudante francês ouvinte foi questionado sobre o mesmo assunto, ele respondeu gostar de tudo na escola, menos das aulas e dos professores, o que, na literalidade, vai de encontro ao que afirmou nosso estudante apenas no que se relaciona ao professor, pois este considerou "aprender com os professores" um dos motivos para ir à escola, diferentemente da resposta obtida por Charlot (2012) dos estudantes franceses. 
Orlandi (2009, p.30) nos relembra que os dizeres "têm a ver com o que é dito ali, mas também em outros lugares", ou seja, dependendo do momento e do contexto do meu discurso e de para quem me dirijo, posso me expressar de diferentes formas. Com efeito, quando questionado sobre:

\section{E: O que mais gostava na escola e o que menos gostava?}

E1: Mais gosto da aula de educação física, biologia e aula de matemática, que eu entendo mais e gostava de conversar com todos, do meu jeito. E não gostava de algumas matérias que eu não entendia e quando brigavam comigo injustamente.

$\mathrm{E}:$ Que matérias você não gostava e também não entendia?

E1: Não gostava de português, química e nem espanhol. Não gostava e nem entendia.

E: Você teve intérprete em todo o seu ensino médio?

E1: Não, passei um ano sem intérprete no ano passado.

O estudante parece ter encontrado sentido, desejo e prazer em aprender nas aulas de Educação Física, Matemática e Biologia, destacando essas três disciplinas como suas favoritas.

O contexto imediato do discurso do estudante, em um espaço de privacidade, longe da percepção do outro, possibilitou que ele também relatasse seu desapreço pelas disciplinas Português, Química e Espanhol. Assim, a exterioridade do que foi dito só tem sentido dentro de condições determinadas (ORLANDI, 2009).

Por outro lado, a Educação Física, a Matemática e a Biologia parecem se comunicar de uma forma particular e direta com o estudante, uma vez que a Libras, sua língua natural, é de modalidade visual-espacial e, como tal, permitia uma boa interação com essas disciplinas, que se apresentam, de modo geral, para a compreensão do estudante visualmente.

Charlot (2000, p. 64) lembra que "a questão do saber sempre é uma questão identitária”. Assim, o envolvimento do estudante com tais disciplinas parte da sua referência histórica, das suas expectativas (cursar Tecnologia ou Robótica), das suas referências, das suas relações com os professores dessas disciplinas, além da imagem que tem de si.

No discurso do recém-formado do ensino médio sobre sua relação com uma das disciplinas de que mais gostava, matemática, ele nos responde:

E: Desde quando você começou a estudar a matemática, você acha ter aprendido muito sobre a matéria? 
E1: Aprendi muito, sim. Aprendi multiplicar, somar, equações e probabilidade, essas coisas.

E: Complete a frase: a matemática é importante porque...

E1: Porque sempre vou precisar dela na minha vida.

E: Você lembra de algum assunto que mais te marcou na matemática?

E1: Definição de igualdade.

E: Pode me explicar o que seria igualdade na matemática?

E1: Na matemática a definição de igualdade diz que dois objetos são iguais.

Para Charlot (200o), os estudantes são sujeitos de desejo, que percebem e interpretam o mundo com os sentidos, têm uma história pessoal, ocupam um lugar, exercem uma atividade e são sujeitos que têm no seu mais íntimo a característica social. Portanto, para compreender o que ocorre na escola e quais as relações desse estudante com a matemática e o fato de aprender, é preciso levar em consideração que ele é um sujeito, antes mesmo da sua deficiência, que o marca diante de uma sociedade que padroniza e distribui rótulos.

Nesse contexto, Nascimento (2018) afirma que o íntimo da questão está em um aprender gerador de sentido, desejo, prazer, significado, que estimule um esforço pessoal, uma vez que, para aprender, é preciso estar “disposto a” se envolver, questionar, mudar, compreender seu tempo e momento na dinâmica escolar, além da percepção de uma ação que realmente faça sentido para ele estar ali, naquele contexto, naquela situação, naquele tempo. Sem esses ingredientes os estudantes são fadados a permanecer em uma sala de aula "fingindo aprender" e os professores, "fingindo ensinar".

Diante da importância do intérprete no seu processo educacional, o estudante nos afirma:

E: Qual importância você dá aos intérpretes na sua formação?

E1: Eles são muito importantes para a gente surdos, porque sem eles não daria para aprender nada na escola. Eles fazem a mediação da aula, sem eles, não daria para aprender nada, como já aconteceu, quando fiquei sem intérprete.

E: Desde quando você entrou na escola, teve algum professor ou alguma pessoa em especial que te levou a ter mais interesse nas aulas?

E1: Os intérpretes que tive desde pequeno e minha amizade com eles, me fizeram eu ter mais vontade de estudar, porque me ajudavam muito em tudo, principalmente, quando eu ficava desanimado, eles me incentivavam. 
Para Orlandi (2009, p. 33), "todo dizer, na realidade, se encontra na confluência dos dois eixos: o da memória (constituição) e o da atualidade (formulação)”. Ou seja, não existe um dizer largado, solto, desconexo da situação de enunciação, do lugar enunciado e da sua historicidade. Assim, o interdiscurso também é historicidade; é memória; é filiação de dizeres. É na perspectiva desses dois eixos que se forma a dinâmica do sentido trazido na fala do estudante entrevistado.

Segundo ele, o intérprete representou a concretização de um ensino que lhe permitiu investir, fazer uso de si como recurso e reunir forças para se envolver na lógica simbólica da escola. Nessa perspectiva, o estudante encontrou suas próprias razões, que o foi colocando diante de um desejo, um sentido e um valor escolar durante o processo educacional.

\section{CONCLUSÃo}

Esta pesquisa identifica, a partir de um estudo exploratório descritivo, que o papel do intérprete de Libras em sala de aula está relacionado com a intermediação do saber experienciado pelo professor por meio de suas metodologias, e também com a inclusão comunicativa social e cultural do estudante surdo no espaço escolar, o que lhe permite adquirir e se aproximar do patrimônio cultural construído pela humanidade e, ao mesmo tempo, cria condições para que possa se relacionar com o outro e com o mundo.

Nesse contexto, a qualidade dos atos educacionais em uma sala de aula que apresenta os três protagonistas do mencionado triângulo pedagógico reinterpretado - professor, intérprete e o estudante - está ligada: ao sentido que o professor encontra na sua profissão, no seu desejo e prazer em mudar, de alguma forma, a realidade social e cultural dos seus estudantes, por ele também ser responsável pela aprendizagem dos estudantes; à formação do profissional intérprete de Libras, que precisa atender às exigências prático-operativas em sala de aula; ao estudante, um ser singular e social, que tem uma história, interpreta o mundo, dá um sentido a esse mundo, articula-se com os objetivos do processo de ensino e aprendizagem a serem atingidos a partir de práticas pedagógicas que respeitem a identidade própria da língua de sinais, para que estudantes surdos construam relações sociais de saber.

Diante do exposto, alguns dos resultados da presença do intérprete de Libras a partir do discurso do estudante podem ser resumidos em quatro ideias: "aprender", pois, segundo o estudante, sem a presença do intérprete ele não teria condições de aprender nada na escola; "mais vontade de estudar", uma vez que o profissional 
intérprete apresentava o saber ao estudante; "ajudar", porque o profissional era o seu grande apoio e incentivador pedagógico na escola pública; e "Eles fazem a mediação da aula”, em virtude da qualificação profissional do intérprete.

É importante ressaltar que o presente estudo também aponta para um equívoco social, ao tratar a inclusão da pessoa surda na escola pública apenas como sinônimo de garantia do seu acesso a esses espaços, através da sua matrícula, tal como a presença do intérprete de Libras na sala de aula como garantia e efetivação da inclusão. Na verdade, existem outras demandas pedagógicas tão importantes quanto as mencionadas - por exemplo, a formação de professores que explore metodologias acessíveis, materiais didáticos disponíveis nas escolas públicas, suas estruturas arquitetônicas, dentre outros - que, em conjunto, podem formar uma frente de ações atitudinais para um processo educacional inclusivo dentro das escolas.

Portanto, a garantia da matrícula e a presença do intérprete são reconhecidas como um avanço civilizatório no processo educacional da pessoa surda, assim como a formação desse profissional é fundamental. Mas também é preciso que as escolas públicas ofereçam condições para que a relação construída pelo duplo triângulo pedagógico reinterpretado nesta pesquisa possa se desenvolver de forma harmoniosa, de maneira que o processo de ensino e aprendizagem siga os princípios da equidade de oportunidades de todos os estudantes.

\section{REFERÊNCIAS}

ARRUDA, S. M.; PASSOS, M. M. A relação com o saber na sala de aula. In: COLÓQUIO INTERNACIONAL EDUCAÇÃO E CONTEMPORANEIDADE, 11., Aracaju, 2015. Anais... Disponível em: http://educonse.com.br/ixcoloquio/arruda_passos2.pdf. Acesso em: 05 out. 2020.

BRASIL. Lei $n^{\circ}$ 12.796, de 4 de abril de 2013. Altera a Lei $n^{\circ}$ 9.394, de 20 de dezembro de 1996, que estabelece as diretrizes e bases da educação nacional, para dispor sobre a formação dos profissionais da educação e dar outras providências. Disponível em: http://www.planalto.gov. br/ccivil_03/_Ato2011-2014/2013/Lei/L12796.htm. Acesso em: 20 out. 2020.

BRASIL. Lei no 13.146, de 6 de julho de 2015. Institui a Lei Brasileira de Inclusão da Pessoa com Deficiência (Estatuto da Pessoa com Deficiência). Disponível em: http://www.planalto.gov.br/ ccivil_03/_ato2015-2018/2015/lei/l13146.htm. Acesso em: 02 fev. 2019.

CHARLOT, B. Da relação com o saber: elementos para uma teoria. Porto Alegre: Artmed, 2000.

CHARLOT, B. Relação com o saber, formação de professores e globalização: questões para a educação hoje. Porto Alegre: Artmed, 2005.

CHARLOT, B. A mobilização no exercício da profissão docente. Revista Contemporânea de Educação, Rio de Janeiro, v. 7, n. 13, jan./jul. 2012. 
CHEVALLARD, Y. La transposición didáctica: del saber sabio al saber enseñado. Buenos Aires: Aique Grupo Editor, 2005.

CORREIA, E. S.; SILVA, V.A.; NASCIMENTO, W. R. S.; CHARLOT, Y. C. A unidade dialética ensino e aprendizagem: um processo não linear. Revista Internacional Educon, v. I, n. 1, set. 2020. e20011009. CHIZZOTTI, A. Pesquisa qualitativa em ciências humanas e sociais. Petrópolis: Vozes, 2006.

FIORIN, J. L. Duas concepções de enunciação. Estudos Semióticos, São Paulo. Dossiê temático "Semiótica e Psicanálise", v. 16, n. 1, p. 122-137, jul. 2020. Online. Disponível em: https://www. revistas.usp.br/esse. Acesso em: 20 nov. 2020.

FLICK, U. Desenho da pesquisa qualitativa. Porto Alegre: Artmed, 2009.

NASCIMENTO, W. R. S. do. Os efeitos da prática do goalball no processo da mobilização da aprendizagem de alguns fenômenos e conceitos físicos da mecânica para alunos com deficiência visual nas aulas de física. 2018. 182f. Dissertação (Mestrado em Educação para a Ciência) - Universidade Estadual Paulista "Júlio de Mesquita Filho", São Paulo, 2018.

NASCIMENTO, W. R. S. do; CAMARGO, E. P.; CORREIA, E. S.; SILVA, V. A. Ensino de física interdisciplinar para alunos com deficiência visual: a relação com o saber por meio da prática do goalball. Revista de Estudos de Cultura, v. 5, p. 75-88, 2019.

ORLANDI, E. P. Análise de discurso: princípios \& procedimentos. 8. ed. Campinas: Pontes, 2009. PÊCHEUX, M. O papel da memória. In: ACHARD, P. et al. O papel da memória. Tradução de José Horta Nunes. 3. ed. Campinas: Pontes, 2010.

REILY, L. Escola inclusiva: linguagem e mediação. Campinas, São Paulo: Papirus, 2006.

\section{SOBRE OS AUTORES}

Willdson Robson Silva do Nascimento é licenciado em Física (UFMA 2015), Mestre em Ensino de Ciências (2018) e Doutorando no Programa de Pós-Graduação em Educação para a Ciência pela Universidade Estadual Paulista "Júlio de Mesquita Filho", Campus Bauru. Professor Substituto da Universidade Estadual do Maranhão (UEMA / São Luís). Membro do Grupo de Estudo e Pesquisa Ensino de Ciências e Inclusão Escolar - ENCINE / UNESP / CNPq e Educação e Contemporaneidade - EDUCON / UFS / CNPq. Membro do Comitê Nacional de Divulgação da Astronomia (IAU - NOCBrasil). Monitor do Observatório Didático de Astronomia da Unesp/Bauru.

ORCID ID: https://orcid.org/oooo-0oo2-2350-7731.

E-mail: willdson.robson@unesp.br.

Eder Pires de Camargo possui Licenciatura em Física (1995), Mestrado em Educação para a Ciência (2000), Doutorado em Educação (2005) pela Universidade Estadual de Campinas - UNICAMP e Pós-Doutorado (2006) pela 
Universidade Estadual Paulista - UNESP. É Livre-Docente do Departamento de Física e Química da UNESP, e atua no PPG - Mestrado e Doutorado em Educação para a Ciência - UNESP/Bauru. Líder do grupo de Estudo e Pesquisa Ensino de Ciências e Inclusão Escolar - ENCINE / UNESP / CNPq.

ORCID ID: http://orcid.org/oooo-0003-2577-9885.

E-mail: eder.camargo@unesp.br.

Eanes dos Santos Correia é licenciado em Educação Física (2011), Mestre em Ensino de Ciências Naturais e Matemática (2017) e Doutorando em Educação pela Universidade Federal de Sergipe. Membro do Grupo de Estudo e Pesquisa Educação e Contemporaneidade - EDUCON / UFS / CNPq.

ORCID ID: http://orcid.org/oooo-0oo2-9188-4336.

E-mail: eanescorreia1@gmail.com.

Recebido em 16 de fevereiro de 2021 e aprovado em 14 de julho de 2021. 